\title{
Methods of deliberate self-harm in a tertiary hospital in South Africa
}

\begin{tabular}{|c|c|c|c|}
\hline \multirow{11}{*}{\multicolumn{2}{|c|}{ 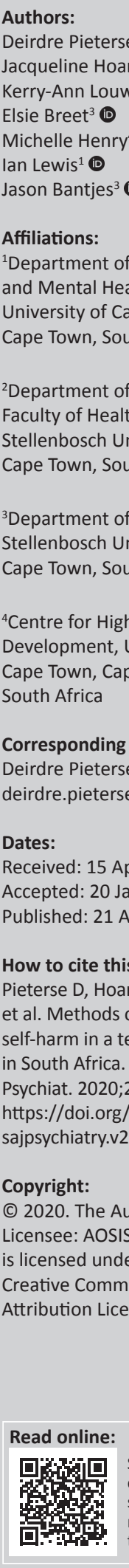 }} & & $\begin{array}{l}\mathrm{e}^{1} \text { (D) } \\
\mathrm{re}^{1} \text { (D) } \\
\mathrm{v}^{2} \text { (D) } \\
{ }^{4} \text { (D) } \\
\text { (D) }\end{array}$ \\
\hline & & & $\begin{array}{l}\text { f Psychiatry } \\
\text { alth, } \\
\text { ape Town, } \\
\text { uth Africa }\end{array}$ \\
\hline & & & $\begin{array}{l}\text { f Psychiatry, } \\
\text { th Sciences, } \\
\text { niversity, } \\
\text { uth Africa }\end{array}$ \\
\hline & & & $\begin{array}{l}\text { f Psychology, } \\
\text { niversity, } \\
\text { uth Africa }\end{array}$ \\
\hline & $\begin{array}{l}\text { sher Education } \\
\text { University of } \\
\text { pe Town, }\end{array}$ & & $\begin{array}{l}\text { her Education } \\
\text { University of } \\
\text { pe Town, }\end{array}$ \\
\hline & & & $\begin{array}{l}\text { author: } \\
\text { e, } \\
\text { e@gmail.com }\end{array}$ \\
\hline & $\begin{array}{l}\text { Apr. } 2019 \\
\text { an. } 2020 \\
\text { Apr. } 2020\end{array}$ & & $\begin{array}{l}\text { pr. } 2019 \\
\text { an. } 2020 \\
\text { pr. } 2020\end{array}$ \\
\hline & $\begin{array}{l}\text { is article: } \\
\text { are J, Louw K-A, } \\
\text { of deliberate } \\
\text { tertiary hospital } \\
\text { S Afr J } \\
\text {;26(0), a1399. } \\
/ 10.4102 / \\
26 i 0.1399\end{array}$ & & $\begin{array}{l}\text { s article: } \\
\text { re J, Louw K-A, } \\
\text { of deliberate } \\
\text { ertiary hospital } \\
\text { S Afr J } \\
26(0) \text {, a1399. } \\
10.4102 / \\
6 i 0.1399\end{array}$ \\
\hline & & & $\begin{array}{l}\text { uthors. } \\
\text { this work } \\
\text { er the } \\
\text { ons } \\
\text { nse. }\end{array}$ \\
\hline & & & \\
\hline & & & $\begin{array}{l}\text { Scan this QR } \\
\text { code with your } \\
\text { smart phone or } \\
\text { mobile device } \\
\text { to read online. }\end{array}$ \\
\hline
\end{tabular}

Background: Little is known about the methods of deliberate self-harm (DSH) in South Africa (SA), despite the importance of means restriction as a public health strategy to reduce the morbidity and mortality associated with self-harm.

Aim: The aim of this study was to investigate the range of methods used in DSH and identify the socio-demographic and clinical factors associated with violent and non-violent methods of DSH among patients treated at a tertiary hospital in SA.

Setting: The study was conducted at an urban, tertiary level emergency department at Groote Schuur hospital in Cape Town, South Africa.

Method: Data were collected from 238 consecutive DSH patients who presented for emergency department treatment at the hospital. Logistic regression models were used to explore the factors associated with violent and non-violent methods of DSH.

Results: Self-poisoning was the most common method of self-harm (80.3\%). Prescription medication was the most common form of self-poison $(57.6 \%)$, while a large number of patients used non-prescription paracetamol $(40.9 \%)$. In the regression analysis, male gender, stating that the reason for DSH was to escape a situation and history of substance use were associated with violent method of DSH.

Conclusion: Improved monitoring of prescription medications commonly used in DSH is integral to public health suicide prevention strategies in SA. This study underscores the need for substance use interventions in the healthcare setting.

Keywords: deliberate self-harm; non-fatal suicide; general hospital; mental health; methods of self-harm; means restriction; suicide prevention.

\section{Introduction}

In South Africa (SA), suicide is a serious public health concern ${ }^{1}$ accounting for approximately $9.6 \%$ of unnatural deaths and yielding an annual prevalence rate of 13.25 per $100000 .^{2}$ Studies in this country have consistently shown that common methods of suicide are hanging, firearms and poisoning. ${ }^{2,3,4}$ Globally, 30\% of all fatal suicide attempts are because of pesticide self-poisoning, occurring most frequently in rural agricultural areas. ${ }^{5}$

Researchers recognise the confusing and often contradictory definitions of suicide and suicide behaviour in the literature. ${ }^{6}$ Inadequate definitions in suicide research often limit the generalisability of findings. The term suicidal behaviour has a broader meaning than suicide and encompasses a range of emotions, cognitions and actions, all of which are characterised by a conscious desire to die. ${ }^{2}$ A distinction is also made between 'deliberate self-harm (DSH) with intent to die' (i.e. attempted suicide) and other forms of repetitive self-harm (such as cutting, self-mutilation and hitting) which is self-inflicted, habitual and is carried out without any conscious intention to die. Deliberate self-harm with intent to die is a form of suicidal behaviour. 'Deliberate self-harm' and 'non-fatal suicide' are also referred to as 'suicide attempts' in the literature. The focus of this study is DSH regardless of intent to die.

In the last 15 years, a number of descriptive general hospital-based studies have investigated the epidemiology of DSH in urban and rural hospitals in SA. . $, 8,9,10,11,12,13,14$ The methodological differences across these studies make it difficult to generalise findings; however, data suggest that self-poisoning is the most common method of DSH in SA.

Self-poisoning was found to be the most common method of DSH in international studies conducted in hospital emergency departments (EDs). ${ }^{15,16,17,18,19}$ Prescription medication was the 
most frequently used substance in the cited studies in highincome countries, with the exception of the United Kingdom where paracetamol was the most common medication used in DSH. ${ }^{19}$ Although the correlates and risk factors of DSH have been described in international literature, the factors associated with methods of DSH have not been extensively examined in SA.

Evidence suggests that limiting access to lethal means ('means restriction') is effective in reducing morbidity and mortality. ${ }^{20}$ Furthermore, the World Health Organization (WHO) states that knowledge of the most commonly used suicide methods in a sub-population is important to implement specific suicide prevention strategies. ${ }^{5}$

It is within this context that we set out to investigate the methods of DSH and the socio-demographic and clinical correlates of these methods among patients presenting to a tertiary hospital in SA.

\section{Methods}

This descriptive, cross-sectional study was undertaken in the ED of an urban, tertiary hospital in SA. The study hospital is an 893-bed, government-funded hospital ${ }^{21}$ serving an estimated 1.7 million people. ${ }^{22}$ The majority of patients are referred from a regional or district hospital if they require tertiary care, meaning that the hospital manages more complex patients. The hospital has a 24-h psychiatry service and 40 inpatient beds dedicated to psychiatry supported by four psychiatrists. The hospital serves patients older than 12 years.

Deliberate self-harm was defined using the WHO or Euro Multicentre intervention study on parasuicide definition:

$[A]$ n act with non-fatal outcome, in which an individual deliberately initiates a non-habitual behaviour that, without intervention from others, will cause self-harm, or deliberately ingests a substance in excess of the prescribed or generally recognised therapeutic dosage, and which is aimed at realising changes which the subject desired via the actual or expected physical consequences. ${ }^{23}$

All DSH patients, regardless of the intention of the selfharm, who presented to the ED following an act of DSH were included. The study period was from the 16 June 2014 to March 2015. Data were collected by a registered psychiatric nurse with more than 20 years of experience in emergency psychiatry using a data capture form which was piloted prior to the commencement of the study. Data extraction was reviewed by a $\mathrm{PhD}$ candidate in psychology to ensure that information had been correctly captured from patient records. The presence or absence of a psychiatric diagnosis was assessed from the clinical notes in patients' folders. The study did not use structured clinical interviews to determine a clinical diagnosis and relied on folder diagnoses.

Over this time, there were 270 presentations of DSH of whom 32 were excluded. The exclusions were for the following reasons: death as a result of DSH (five patients), patients who left the hospital prior to data capture, ${ }_{1}^{1}$ missing folders ${ }^{17}$ and patients presenting with DSH for the second time during the study period. ${ }^{9}$

\section{Measures}

The following data were collected from clinical folders and possibly supplemented with patient interview:

- Socio-demographic information. Self-reports of patients' age, gender, race, relationship status and employment status were recorded on a data capture form.

- Method of self-harm. The method of non-fatal self-harm was recorded. A distinction between the use of prescription and non-prescription medications was recorded based on the following definition: prescription medication was defined using the South African Medicines Control Council definition as 'a substance which can only be obtained on the prescription of an authorised prescriber'. ${ }^{24}$ Violent (i.e. those which entailed damage to bodily tissue) and non-violent methods (self-poison) were also recorded.

- Details of self-harm. Self-report data were obtained about reasons given for self-harm and the patient's stated intention for engaging in the behaviour.

- Clinical characteristics and medical interventions. Information about the level of consciousness on admission (as measured by the Glasgow Coma Scale), psychiatric history, history of substance use and current psychiatric diagnosis were obtained from the patients' files. We also recorded the details of the hospital-based management, including the level of admission and the interventions provided. Level of medical admission was defined by the following categories: admission to intensive care unit (ICU), admission to long-stay medical or surgical ward, admission to short-stay medical ward, admission to emergency psychiatric ward and total number of days spent in hospital. Medical intervention and assessment was defined by whether or not a patient received a medical intervention, assessment by psychologist or psychiatric assessment.

\section{Data analysis}

Descriptive statistics were used to provide epidemiological information about the methods of DSH and the sample characteristics. For the purposes of statistical analysis, we differentiated between violent (damage to bodily tissue) and non-violent (self-poison) methods. Chi-square tests of association were conducted to determine which socio-demographic and clinical variables were associated with the specified method of DSH.

The variables found to be significantly associated with the method of DSH in bivariate analysis were entered into the logistic regression models. Logistic regression analysis was used to determine which factors (demographic and clinical variables) were associated with the use of a violent method 
and non-violent method of DSH. All analyses were conducted using SPSS software (version 24) and the significance level was set at $\alpha=0.05$.

\section{Ethical considerations}

Ethical approval for this study was obtained from the University Human Research Ethics Committee (HREC/REF $687 / 2016)$. Institutional permission to conduct this study in the hospital was obtained from both the Department of Health and the relevant hospital authorities.

\begin{tabular}{|c|c|c|}
\hline Socio-demographic and clinical description of the sample & $n$ & $\%$ \\
\hline \multicolumn{3}{|l|}{ Gender } \\
\hline Male & 96 & 40.3 \\
\hline Female & 142 & 59.7 \\
\hline \multicolumn{3}{|l|}{ Race } \\
\hline Black & 82 & 34.5 \\
\hline Asian & 8 & 3.4 \\
\hline Mixed race & 103 & 43.3 \\
\hline White & 33 & 13.9 \\
\hline Not known & 12 & 5.0 \\
\hline \multicolumn{3}{|l|}{ Home language } \\
\hline Afrikaans & 49 & 20.6 \\
\hline English & 135 & 56.7 \\
\hline isiXhosa & 47 & 19.7 \\
\hline isizulu & 2 & 0.8 \\
\hline Not known & 5 & 2.1 \\
\hline \multicolumn{3}{|l|}{ Relationship status } \\
\hline Married & 42 & 17.6 \\
\hline In a relationship & 4 & 1.7 \\
\hline Single & 171 & 71.8 \\
\hline Divorced & 14 & 5.9 \\
\hline Widowed & 6 & 2.5 \\
\hline Not known & 1 & 0.4 \\
\hline \multicolumn{3}{|l|}{ Number of dependents } \\
\hline No dependants & 155 & 65.1 \\
\hline Dependants & 80 & 33.6 \\
\hline Not known & 43 & 1.3 \\
\hline \multicolumn{3}{|l|}{ Completed level of education } \\
\hline Primary school & 100 & 42.0 \\
\hline Secondary school & 100 & 42.0 \\
\hline Tertiary education & 38 & 16.0 \\
\hline \multicolumn{3}{|l|}{ Employment status } \\
\hline Employed & 51 & 21.4 \\
\hline Student & 46 & 19.3 \\
\hline Unemployed & 130 & 54.6 \\
\hline Retired & 6 & 2.5 \\
\hline Not known & 5 & 2.1 \\
\hline \multicolumn{3}{|l|}{ Socio-economic status } \\
\hline Low-to-moderate income (R0-R76 800) ${ }^{1}$ & 131 & 55.0 \\
\hline High income (R76 801-R2 457 601) & 85 & 35.7 \\
\hline Not known & 22 & 9.2 \\
\hline \multicolumn{3}{|l|}{ Current psychiatric diagnosis } \\
\hline Yes & 143 & 60.1 \\
\hline No & 66 & 27.7 \\
\hline Not known & 29 & 12.2 \\
\hline \multicolumn{3}{|l|}{ History of previous suicidal self-injury } \\
\hline Previous attempt & 89 & 37.4 \\
\hline No previous attempt & 69 & 29.0 \\
\hline Not known & 80 & 33.6 \\
\hline
\end{tabular}

Note: As per Statistics South Africa Census 2011.

\section{Results}

\section{Socio-demographic and clinical characteristics of the sample}

The description of the sample is shown in Table 1. The mean age of the sample was 31.5 years $(\mathrm{SD}=13.9$, range $=13-82)$. More than a third $(37.4 \%)$ of the total sample reported previous suicide attempts.

\section{Methods of self-harm}

The methods of DSH are shown in Table 2. Self-poisoning was the most common method reported in this sample $(80.3 \%)$. The range of medications used in self-poisoning is shown in Table 3. Among patients who reported selfpoisoning, prescription medications were most commonly used (57.6\%). Of the prescription medication, other medication unknown or not specified by the patient (23.5\%), tricyclic antidepressants (12.7\%), anti-hypertensive agents (12.7\%) and benzodiazepines (10.9\%) were most commonly used.

Paracetamol (40.9\%), anti-histamines (12.9\%), other nonprescription medication unknown or not specified by the patient $(12.8 \%)$ and non-steroidal anti-inflammatory drugs (9.1\%) were the most common non-prescription medications used to self-harm. Nineteen (7.9\%) patients reported ingestion or inhalation of poison. Notably, $20 \%$ of patients used both prescription and non-prescription medication, while only one patient used all three self-poison methods. Thirty-four patients (14.3\%) used damage to bodily tissue as a method of DSH. Attempted hanging and laceration to the skin were the most common violent methods of DSH (5.5\%, $n=13)$.

\section{Substance use}

A total of $20.2 \%(n=48)$ patients reported single substance use at the time of the attempt, while $18 \%$ reported polysubstance use. Alcohol (65.5\%, $n=38$ instances of alcohol use) was the most

TABLE 2: Method of deliberate self-harm.

\begin{tabular}{lcc}
\hline Method of deliberate self-harm & $\boldsymbol{n}$ & $\mathbf{\%}$ \\
\hline Self-poison & 191 & 80.3 \\
Prescription medication only & 79 & 33.2 \\
Non-prescription medication only & 38 & 16.0 \\
Ingestion or inhalation of poison & 19 & 7.9 \\
\hline Prescription + non-prescription medication & 49 & 20.6 \\
Prescription medication + ingestion/inhalation & 1 & 0.4 \\
Non-prescription medication + ingestion/inhalation & 4 & 1.7 \\
All three self-poison methods & 1 & 0.4 \\
Damage bodily tissue & 34 & 14.3 \\
Laceration & 13 & 5.5 \\
Hanging & 13 & 5.5 \\
Laceration + hanging & 1 & 0.4 \\
Asphyxiation & 0 & 0.0 \\
Immolation & 0 & 0.0 \\
Jumped off a height & 4 & 1.7 \\
Jumped in front of train & 3 & 1.3 \\
Self-poison and damage bodily tissue & 8 & 3.3 \\
\hline Not known & 5 & 2.1 \\
\hline
\end{tabular}


TABLE 3: Prescription and non-prescription medication taken by patients.

\begin{tabular}{lcc}
\hline Medication type & $\boldsymbol{n}$ & $\mathbf{\%}$ \\
\hline Prescription & 221 & - \\
Other prescription medication unknown or not specified & 52 & 23.5 \\
by the patient benzodiazepines & & \\
Tricyclic antidepressants & 28 & 12.7 \\
Anti-hypertensives & 28 & 12.7 \\
Benzodiazepines & 25 & 11.3 \\
Analgesic medication & 23 & 10.4 \\
SSRI & 18 & 8.1 \\
Anti-epileptic medication & 14 & 6.3 \\
Anti-psychotics & 13 & 5.9 \\
Oral hypoglycaemic agents & 10 & 4.5 \\
Antibiotics & 10 & 4.5 \\
Non-prescription & 141 & - \\
Paracetamol & 54 & 38.3 \\
Other medication unknown or not specified by the patient & 18 & 12.8 \\
Antihistamine & 17 & 12.0 \\
NSAID & 12 & 8.5 \\
Paracetamol and codeine prep & 10 & 7.1 \\
Vitamin compound & 10 & 7.1 \\
Iron tablets & 9 & 6.4 \\
Aspirin & 6 & 4.2 \\
Illicit substance & 5 & 3.5 \\
\hline SSRI, seliv & & \\
\hline
\end{tabular}

SSRI, selective serotonin reuptake inhibitor; NSAID, non-steroidal anti-inflammatory drug.

commonly used substance, while methamphetamine (13.8\%, $n$ $=8)$, cocaine $(6.9 \%, n=4)$, cannabis $(5.2 \%, n=3)$, heroin $(5.2 \%, n$ = 3), methylenedioxymethamphetamine (ecstasy) and opiates $(1.7 \%, n=1$ each) use were also reported. A total of $37.4 \%(n=89)$ of patients reported a history of a substance use disorder.

\section{Stated intention and reason for self-harm}

The degree of intent was reported as follows: $66 \%$ did not express an intention to die, while $34 \%$ indicated an intent to die. Impulsivity was reported in $22.3 \%$ of the sample, while a majority $(87.8 \%)$ reported that the self-harm attempt was non-accidental. Among the total sample, the most common intentions were to communicate something, for example, distress $(34.5 \%, n=82)$, to die $(34 \%, n=81)$, to regulate the behaviour of someone else $(23.1 \%, n=55)$, an impulsive act $(22.3 \%, n=53)$ or to escape a situation $(20.6 \%, n=49)$. Family conflict $(36.6 \%)$ and relationship (friendship, marital or romantic) issues $(31.1 \%)$ were the most common stated reasons for DSH.

Other stated reasons were psychiatric illness (15.1\%) and financial concerns (19.7\%).

\section{Severity of injuries and clinical management of patients}

Of the total sample, $15.5 \%$ were assessed as having a moderateto-severe brain injury (Glasgow Coma Scale < 13) upon arrival at the hospital. Two-thirds of the sample received a medical intervention, and in $71.8 \%$ of the sample, psychotropic medication was initiated. Of the total sample, $84(35 \%)$ patients were seen in the ED and discharged, and 90 (38\%) were admitted to an emergency psychiatric unit (EPU). The 150 patients who were admitted spent a combined total of 1186 days in hospital $($ mean $=6.71$ days, standard deviation $[S D]=9.31)$.

\section{Correlates of violent and non-violent methods of self-harm}

The results of the unadjusted and adjusted regression coefficients of tests of association with methods of DSH are shown in Table 4. Age was analysed as a continuous variable. The mean age of those who used violent methods was 33.62 years (SD 13.36) and for those who used non-violent methods it was 31.28 years (SD 14.25) $(t=-0.89 ; p=0.375)$. Socio-demographic and clinical variables identified as significant in the univariate analyses were entered into a logistic regression model. The regression model was significant, $\chi^{2}(5)=42.938, p<0.001$, Nagelkerke $R^{2}=0.335$. This model accurately predicted use of violent or non-violent DSH method $87 \%$ of the time.

However, in the final step of the regression model, the following variables were no longer significant: patients who stated that their psychiatric illness was the reason for DSH $(p=0.279)$ and patients with a current diagnosis of a psychotic disorder $(p=0.100)$. These variables were therefore removed from the model. The new final regression was significant, $\chi^{2}(3)=38.348, p<0.001$, with Nagelkerke $R^{2}=$ 274 . This model accurately predicted use of violent or nonviolent DSH method $87 \%$ of the time. Male gender, wanting to escape a situation, and a history of substance abuse meant it more likely for someone to use a violent method of DSH. Men were 6.2 times more likely to use a violent method of DSH compared with women. Patients whose intention was to escape a situation were 3.4 times more likely to use a violent method of DSH compared with patients who expressed other intentions. Finally, patients with a history of substance abuse were 3.3 times more likely to use a violent method of DSH compared with patients with no prior history of substance abuse.

\section{Discussion}

Self-poison was the most common method of DSH seen at the hospital over the study period. Prescription medication was the most prevalent form of self-poison, while a significant number of patients used the non-prescription medication paracetamol. This study provides detail on violent methods of DSH in this sample population. In the regression analysis, male gender, stating that the reason for DSH was to escape a situation and history of substance use were associated with violent method of DSH.

The main finding is consistent with the literature: self-poison with possible fatal consequences remains the most common form of DSH worldwide..$^{7,10,16,19}$ Despite the known worldwide burden of self-poisoning and DSH, few standard hospitalbased, mental health intervention protocols exist to manage patients who present with DSH in the ED. ${ }^{25}$

The prevalence of prescription medication in this sample further supports the idea that ingestion of agricultural poison as a method of DSH is less common in urban areas of SA.7,11 Benzodiazepines and anti-depressants are consistently reported as highly prevalent substances used in 
TABLE 4: The unadjusted and final regression coefficients form the bivariate and motivate analysis of factors associated with method of self-harm.

\begin{tabular}{|c|c|c|c|c|c|c|c|}
\hline \multirow[t]{2}{*}{ Predictors of DSH method } & \multicolumn{3}{|c|}{ Unadjusted } & \multicolumn{4}{|c|}{ Adjusted } \\
\hline & $\chi^{2}$ & $p$ & $V$ & Wald statistic & Adjusted odds ratio & $p$ & $95 \% \mathrm{Cl}$ \\
\hline \multicolumn{8}{|l|}{ Socio-demographic factors } \\
\hline Male gender & 28.972 & $<0.001$ & 0.356 & 14.687 & 6.198 & $<0.001$ & $2.438-15.755$ \\
\hline Race & 5.275 & 0.153 & 0.156 & - & - & - & - \\
\hline Relationship status & 0.057 & 0.822 & 0.016 & - & - & - & - \\
\hline Number of dependants & 1.569 & 0.210 & 0.083 & - & - & - & - \\
\hline Completed level of education & 0.465 & 0.793 & 0.045 & - & - & - & - \\
\hline Employment status & 2.594 & 0.459 & 0.108 & - & - & - & - \\
\hline Socio-economic status & 1.750 & 0.186 & 0.092 & - & - & - & - \\
\hline \multicolumn{8}{|l|}{ Clinical factors } \\
\hline History of psychiatric diagnosis & 2.756 & 0.097 & 0.117 & - & - & - & - \\
\hline Current psychotic disorder & 23.157 & $<0.001$ & 0.339 & - & - & - & - \\
\hline Current MDD & 2.262 & 0.133 & 0.106 & - & - & - & - \\
\hline Current adjustment disorder & 0.210 & 0.647 & 0.032 & - & - & - & - \\
\hline Current substance use disorder & 3.776 & 0.052 & 0.137 & - & - & - & - \\
\hline Current anxiety disorder & 0.524 & 0.469 & 0.051 & - & - & - & - \\
\hline Current bipolar disorder & 0.394 & 0.530 & 0.044 & - & - & - & - \\
\hline Current personality disorder & 1.507 & 0.220 & 0.086 & - & - & - & - \\
\hline History of previous DSH & 0.444 & 0.505 & 0.054 & - & - & - & - \\
\hline History of substance abuse & 20.857 & $<0.001$ & 0.302 & - & - & - & - \\
\hline Substance use during DSH & 1.527 & 0.217 & 0.085 & 7.710 & 3.288 & 0.005 & $1.419-7.617$ \\
\hline \multicolumn{8}{|l|}{ Stated intention for DSH } \\
\hline To escape a situation & 4.037 & 0.045 & 0.133 & 6.394 & 3.432 & 0.011 & $1.320-8.926$ \\
\hline To die & 0.097 & 0.756 & 0.021 & - & - & - & - \\
\hline To regulate the behaviour of someone else & 2.795 & 0.095 & 0.111 & - & - & - & - \\
\hline To regulate own emotional state & 0.335 & 0.563 & 0.038 & - & - & - & - \\
\hline To communicate something & 0.385 & 0.535 & 0.041 & - & - & - & - \\
\hline Implosive act (anger) & 1.137 & 0.286 & 0.071 & - & - & - & - \\
\hline Intention unknown & 0.408 & 0.523 & 0.042 & - & - & - & - \\
\hline Other intention & 1.614 & 0.204 & 0.084 & - & - & - & - \\
\hline \multicolumn{8}{|l|}{ Stated reason for DSH } \\
\hline Psychiatric illness & 9.983 & 0.002 & 0.209 & - & - & - & - \\
\hline Financial concerns & 0.050 & 0.823 & 0.015 & - & - & - & - \\
\hline Relationship issue & 1.996 & 0.158 & 0.094 & - & - & - & - \\
\hline Family conflict & 1.844 & 0.175 & 0.090 & - & - & - & - \\
\hline Medical illness & 0.054 & 0.817 & 0.015 & - & - & - & - \\
\hline Bereavement & 0.084 & 0.772 & 0.019 & - & - & - & - \\
\hline Academic concerns & 0.128 & 0.720 & 0.024 & - & - & - & - \\
\hline Social issues & 0.478 & 0.490 & 0.046 & - & - & - & - \\
\hline Unplanned pregnancy & 0.608 & 0.436 & 0.052 & - & - & - & - \\
\hline Mistake & 0.608 & 0.436 & 0.052 & - & - & - & - \\
\hline Reason unknown & 1.341 & 0.247 & 0.077 & - & - & - & - \\
\hline Other reason & 0.388 & 0.533 & 0.041 & - & - & - & - \\
\hline Constant & - & - & - & 56.290 & 0.027 & $<0.001$ & - \\
\hline
\end{tabular}

DSH, deliberate self-harm; MDD, major depressive disorder; PTSD, post-traumatic stress disorder.

DSH worldwide. ${ }^{16,19,26}$ This study replicates this finding in SA and it has important implications for public health intervention regarding medicine control. In this study, tricyclic antidepressants, anti-hypertensive agents and benzodiazepines were the most frequently used medications, which correlates the findings of Raubenheimer and Jenkins. ${ }^{11}$

Paracetamol remains readily available in unlimited quantities in supermarkets and pharmacies in SA, and consistent with local studies, a significant number of patients used paracetamol as a method of DSH. ${ }^{7,8}$ In the United Kingdom, a decrease in the frequency of paracetamol overdoses was observed when the tablets became available exclusively in blister pack form. ${ }^{27}$ As most acts of DSH are impulsive, it is proposed that limiting the quantity of tablets and increasing the time needed to ingest a toxic dose may allow time for reflection. This method of 'means restriction' has now become a recognised strategy for suicide prevention globally. ${ }^{28}$

Violent methods of DSH have largely been under-reported in hospital-based studies in SA. Congruent with data showing that hanging is the most prevalent method of fatal suicide in $\mathrm{SA}^{2}$ attempted hanging was one of the most 
common methods of violent DSH seen in this sample. Our study found no incidents involving firearms and a relatively small number of patients who jumped from a height. This result may be explained by the high mortality associated with these methods. Although only $11 \%$ of patients in our study used both violent and non-violent methods of DSH, Haw et al. ${ }^{29}$ reported that this group has a higher suicidal intent and clinicians should be mindful of this when planning care and follow-up of this sub-group of patients.

The gender difference in choice of DSH method is in keeping with the SA data on fatal suicides. Men tend to use more violent methods of suicide such as hanging, while women are more likely to choose self-poisoning. ${ }^{30}$ In a study based in the United Kingdom, violent method of DSH was associated with high suicidal intent ${ }^{29}$ and researchers from both the USA and Norway have reported that patients who used a violent method are more likely to attempt and complete suicide in future. $^{31,32}$ The authors found no significant associations between method of DSH and other socio-demographic factors such as age, employment or socio-demographic status.

This research finding that history of substance use is associated with violent method of DSH adds to the literature on the strong relationship between substance use and subsequent DSH. Harmful use of alcohol is historically a well-known risk factor for DSH and recent research continues to confirm this association in both hospital- and general population-based studies. ${ }^{33,34,35}$

Previous hospital-based research in SA has identified relationship difficulties, financial distress and distress at home as common reasons for DSH..$^{71,12}$ In this study patients who stated that they wanted to escape a situation were more likely to use a violent method of DSH. This finding adds to the growing body of literature exploring the reasons for and correlates of DSH.

patients who stated that they wanted to escape a situation were more likely to use a violent method of DSH add to this growing body of the literature exploring the reasons for and correlates of DSH.

This study has several limitations. Firstly, the study was conducted in one tertiary hospital in the Western Cape which limits the generalisability of our findings. However, this study adds to the literature on methods used in DSH in SA and hospitals provide a unique opportunity to study this high-risk and understudied population. Secondly, we did not gather information on the source of the prescription medication used in DSH.

This information could be valuable to guide public health interventions and make recommendations to the local Medicines Control Council. Thirdly, personality profiles of the participants were not assessed. Finally, the cross-sectional design of the study limits our ability to comment on the direction of the associations in the regression analysis.

\section{Conclusion}

This study contributes to emerging literature on methods used in DSH in SA. There is a need for the continual monitoring of methods of DSH and the collection of accurate and current epidemiological data about self-harm in SA. The population of DSH patients is continually evolving and the methods of self-harm change in response to dynamic factors, including the availability of means. It is of concern that self-poison and specifically prescription medication were highly prevalent methods of DSH in this population. There is an urgent need for more research on the source of prescription medication and its relationship to DSH. Limiting the quantity and reviewing the packaging of paracetamol available in supermarkets are effective strategies of means restriction that should be adopted in SA.

\section{Acknowledgements}

The authors would like to express their sincere gratitude to all the project research assistants and students who spent countless hours collecting and reading the data. They are grateful to all the patients who shared a snapshot of their often difficult lives with them. The authors believe that this research will enable them to improve mental healthcare in a meaningful way.

\section{Competing interests}

The authors declare that there are no conflicts of interest with regard to the writing of this article.

\section{Authors' contributions}

J.B., K.L. and I.L. contributed to the research design and data collection of the larger study on which this sub-study is based. D.P., K.L., J.H. and J.B. made substantial contributions to the article conception, design and interpretation of data. M.H., D.P. and E.B. made substantial contributions to data management, analysis and interpretation of data. D.P. prepared the first draft of the article. All authors critically reviewed and approved the final version of the article.

\section{Funding information}

The work presented in this article was made possible through funding by theSouth African Medical Research Council (SAMRC) via its Division of Research Capacity Development under the Mid-Career Scientist Programme (awarded to J.B.). The views expressed herein do not reflect the views of the SAMRC.

\section{Data availability statement}

Data sharing is not applicable to this article as no new data were created or analysed in this study.

\section{Disclaimer}

The views and opinions expressed in this article are those of the authors and do not necessarily reflect the official policy or position of any affiliated agency of the authors. 


\section{References}

1. Schlebusch L. Suicide prevention: A proposed national strategy for South Africa. Afr J Psychiatry. 2012;15(6):436-440. https://doi.org/10.4314/ajpsy.v15i6.56

2. Bantjes J, Kagee A. Epidemiology of suicide in South Africa: Setting an agenda for future research. S Afr J Psychol. 2013;43(2):238-251. https://doi.org/10.1177/ 0081246313482627

3. Naidoo SS, Schlebusch L. Sociodemographic characteristics of persons committing suicide in Durban, South Africa: 2006-2007. Afr J Prim Heal Care Fam Med. 2014;6(1):E1-E7. https://doi.org/10.4102/phcfm.v6i1.568

4. Scribante L, Blumenthal R, Saayman G, Roos JL. A retrospective review of 1018 suicide cases from the capital city of South Africa for the period 1997-2000. Am J Forensic Med Pathol. 2004;25(1):52-55. https://doi.org/10.1097/01.paf.0000113862. $03302.1 \mathrm{~d}$

5. World Health Organization. World Health Organisation: Suicide fact sheet [homepage on the Internet]. 2018 [cited 2018 Feb 8]. Available from: http://www. who.int/mediacentre/factsheets/fs398/en/

6. Silverman MM, Berman AL, Sanddal ND, O'Carroll PW, Joiner TE. Rebuilding the tower of babel: A revised nomenclature for the study of suicide and suicidal behaviors part 1: Background, rationale, and methodology. Suicide Life Threat Behav. 2007;37(3):248-263. https://doi.org/10.1521/suli.2007.37.3.248

7. Du Toit EH, Kruger JM, Swiegers SM, et al. The profile analysis of attemptedsuicide patients referred to Pelonomi Hospital for psychological evaluation and
treatment from 1 May 2005 to 30 April 2006. S Afr J Psychiatry. 2008;14(1):20-26. https://doi.org/10.4102/sajpsychiatry.v14i1.40

8. Favara DM. The burden of deliberate self-harm on the critical care unit of a periurban referral hospital in the Eastern Cape: A 5-year review of 419 patients. S Afr Med J. 2013;103(1):40-43. https://doi.org/10.7196/SAMJ.6231

9. Moosa Y, Jeenah Y, Pillay A, Vorster M, Liebenberg R. Non-fatal suicidal behaviour at the Johannesburg General Hospital. Afr J Psychiatry. 2005;8(3):104-107. https:// doi.org/10.4314/ajpsy.v8i3.30192

10. Nakin $D$, Joubert $G$, Pretorius $P$, Van Vuuren $M$. Evaluation of attempted-suicide management in a rural district of KwaZulu-Natal. S Afr J Psychiatry. 2007;13(2):5255. https://doi.org/10.4102/sajpsychiatry.v13i2.28

11. Raubenheimer L, Jenkins LS. An evaluation of factors underlying suicide attempts in patients presenting at George Hospital emergency centre. South African Fam Pract. 2015;57(2):93-99. https://doi.org/10.1080/20786190.2014.976944

12. Ani JO, Ross AJ, Campbell LM. A review of patients presenting to accident and emergency department with deliberate self-harm, KwaZulu-Natal, South Africa. Afr J Prim Heal Care Fam Med. 2017;9(1):1234. https://doi.org/10.4102/phcfm. v9i1.1234

13. Uys H. Agents used and profiles of non-fatal suicidal behaviour in Mdantsane East London: Part 1. Afr J Psychiatry. 2014:17:128. https://doi.org/10.4172/ Psychiatry.1000128

14. Sukeri K. Common agents used in parasuicide in Buffalo City. S Afr J Psychiatry. 2009;15(3):63-66. https://doi.org/10.4102/sajpsychiatry.v15i3.196

15. Ting SA, Sullivan AF, Boudreaux ED, Miller I, Camargo CAJ. Trends in US emergency department visits for attempted suicide and self-inflicted injury, 1993-2008. Gen Hosp Psychiatry. 2012;34(5):557-565. https://doi.org/10.1016/j.genhosppsych. 2012.03.020

16. Bilen $\mathrm{K}$, Ottosson $\mathrm{C}$, Castren $\mathrm{M}$, et al. Deliberate self-harm patients in the emergency department: Factors associated with repeated self-harm among 1524 patients. Emerg Med J. 2011;28(12):1019-1025. https://doi.org/10.1136/emj. 2010.102616

17. Sendra-Gutiérrez JM, Esteban-Vasallo M, Domínguez-Berjón MF. Suicidal behaviour characteristics and factors associated with mortality in the hospita setting. Rev Psiquiatr Salud Ment. 2018;11(4):234-243. https://doi.org/10.1016/j. rpsm.2016.03.004
18. Chihara I, Ae R, Kudo Y, et al. Suicidal patients presenting to secondary and tertiary emergency departments and referral to a psychiatrist: A population-based descriptive study from Japan. BMC Psychiatry, 2018:18(1):112. https://doi. descriptive study from Japan.
org/10.1186/s12888-018-1690-2

19. Hawton K, Bergen H, Casey D, et al. Self-harm in England: A tale of three cities. Soc Psychiatry Psychiatr Epidemiol. 2007;42(7):513-521. https://doi.org/10.1007/ s00127-007-0199-7

20. Yip PSF, Caine E, Yousuf S, Chang S-S, Wu KC-C, Chen Y-Y. Means restriction for suicide prevention. Lancet. 2012;379(9834):2393-2399. https://doi.org/10.1016/ S0140-6736(12)60521-2

21. Western Cape Government. Western Cape Government [homepage on the Internet]. Department of Health. 2014 [cited 2016 Apr 27]. Available from: https://www.westerncape.gov.za/your_gov/163

22. Department of Health Western Cape. Comprehensive service plan for the implementation of Healthcare 2010 [homepage on the Internet]. 2007 [cited 2016 Aug 23]. Available from: https://www.westerncape.gov.za/text/2007/7/ may15,2007-csp_2.pdf

23. Platt $S$, Bille-Brahe $U$, Kerkhof A, et al. Parasuicide in Europe: The WHO/EURO multicentre study on parasuicide. I. Introduction and preliminary analysis for multicentre study on parasuicide. I. Introduction and preliminary analysis for
1989. Acta Psychiatr Scand. 1992;85(2):97-104. https://doi.org/10.1111/j.16001989. Acta Psychiatr

24. Hela M. Scheduling of Medicines [homepage on the Internet]. Medicine Controls Council. 2014 [cited 2017 Sep 27]. Available from: http://www.mccza.com/ documents/a56714ff2.36_Scheduling_of_Medicines_Jun14_v1.pdf

25. World Health Organization. mhGAP intervention guide for mental, neurological and substance use disorders in non-specialized health settings: Mental health Gap Action Programme [homepage on the Internet]. Version 2.0. 2016 [cited 2017 Dec 11]. p. 131-40. Available from: http://apps.who.int/iris/bitstream/10665/250239/ 1/9789241549790-eng.pdf?ua=1

26. Aguilera P, Garrido M, Lessard E, et al. Medication overdoses at a public emergency department in Santiago, Chile. West J Emerg Med. 2016;17(1):75. https://doi. org/10.5811/westjem.2015.11.26068

27. Turvill JL, Burroughs AK, Moore KP. Change in occurrence of paracetamol overdose in UK after introduction of blister packs. Lancet. 2000;355(9220):2048-2049. https://doi.org/10.1016/S0140-6736(00)02355-2

28. Zalsman $G$, Hawton $K$, Wasserman $D$, et al. Suicide prevention strategies revisited 10-year systematic review. The Lancet Psychiatry. 2016;3(7):646-659. https://doi. org/10.1016/S2215-0366(16)30030-X

29. Haw C, Casey D, Holmes J, Hawton K. Suicidal intent and method of self-harm: A large-scale study of self-harm patients presenting to a general hospital. Suicide Life Threat Behav. 2015;45(6):732-746. https://doi.org/10.1111/sltb.12168

30. Ajdacic-Gross V, Weiss MG, Ring M, et al. Methods of suicide: International suicide patterns derived from the WHO mortality database. Bull World Health Organ. 2008;86(9):726-732. https://doi.org/10.2471/BLT.07.043489

31. Fedyszyn IE, Erlangsen A, Hjorthøj C, Madsen T, Nordentoft M. Repeated suicide attempts and suicide among individuals with a first emergency department contact for attempted suicide: A prospective, nationwide, Danish register-based study. Clin Psychiatry. 2016;77(6):832-840. https://doi.org/10.4088/JCP.15m09793

32. Olfson $M$, Wall $M$, Wang $S$, Crystal $S$, Gerhard T, Blanco C. Suicide following deliberate self-harm. Am J Psychiatry. 2017;174(8):765-774. https://doi.org/ 10.1176/appi.ajp.2017.16111288

33. Arias SA, Dumas O, Sullivan AF, Boudreaux ED, Miller I, Camargo Jr CA. Substance use as a mediator of the association between demographics, suicide attempt history, and future suicide attempts in emergency department patients. Crisis. 2016;37(5):385-392. https://doi.org/10.1027/0227-5910/a000380

34. Fekadu A, Medhin G, Selamu M, et al. Non-fatal suicidal behaviour in rura Ethiopia: A cross-sectional facility-and population-based study. BMC Psychiatry. 2016;16(1):75. https://doi.org/10.1186/s12888-016-0784-y

35. Poorolajal J, Haghtalab T, Farhadi M, Darvishi N. Substance use disorder and risk of suicidal ideation, suicide attempt and suicide death: A meta-analysis. J Public Health. 2016;38(3):282-291. https://doi.org/10.1093/pubmed/fdv148 